\title{
Variation in the CFF with Glycaemic Control in Type 2 Diabetes Mellitus Patients
}

\author{
Gopi Kumar M.S. ${ }^{1}$, Rekha K.N. ${ }^{2}$, Jamuna B.L. ${ }^{3}$, Prem Jayarajan ${ }^{4}$ \\ ${ }^{1}$ Associate Professor, Department of Physiology, Xavier University School of Medicine, Aruba, ${ }^{2}$ Assistant \\ Professor, ${ }^{3}$ Professor and HOD, Department of Physiology, Rajarajeswari Medical College \& Hospital, \\ Bengaluru, ${ }^{4}$ Retired Professor, Department of Physiology, Sapthagiri Medical College and Hospital
}

\begin{abstract}
Introduction: India has a large number of diabetic patients and there is a steep rise in the incidence of diabetes in the last decade. Diabetic control is categorized as poor control (HbAlc levels above 7\%) and good control (HbAlc levels below 7\%). Critical flicker fusion frequency (CFF) is a non-invasive test, which could help early detection of retinal dysfunction and optic neuropathic changes in Type 2 diabetes mellitus (T2DM).
\end{abstract}

Objective: To compare the CFF between

Group 1: T2DM (HbA1c < 7\%).

Group 2: T2DM (HbA1c >7\%).

Methodology: Sixty diagnosed T2DM patients were the subjects in this study. Thirty patients had their $\mathrm{HbA} 1 \mathrm{c}<7 \mathrm{~g} \%$ and $30>7 \mathrm{~g} \%$. The patients were recruited from Medicine department, Rajarajeswari Medical College and Hospital. CFF was measured using an in-house built apparatus. CFF values were noted and then analyzed.

Results and Discussion: The mean CFF in group I and the group II patients were $30.17+4.69 \mathrm{~Hz}$ and $26.32+6.70 \mathrm{~Hz}$, respectively. This was highly significant $(\mathrm{P}=0.012)$. The significantly lower $\mathrm{CFF}$ in the poorly controlled group II diabetics can be attributed to poorglycemic control in that group.

Keywords: Critical Flicker Fusion Frequency, Diabetes Mellitus, Glycosylated Hemoglobin.

\section{Introduction}

Diabetes mellitus is a group of metabolic disorders characterized by hyperglycemia resulting from defects in insulin secretion, insulin action or both. This metabolic disorder is the most prevalent, non-communicable disease in the world. ${ }^{1}$

\section{Corresponding Author:}

Rekha K.N.

Assistant Professor, Department of Physiology,

Rajarajeswari Medical College \& Hospital, Bengaluru

Ph: 9481789249

e-mail: drrekhamanu.physio@gmail.com
The global prevalence of diabetes is estimated to be 463 million people which accounts to around $9.3 \%$ of world population in 2019. The global prevalence of diabetes increases to $19.9 \%$ in the age group of $65-79$ years. This data is collected from the prevalence data of diabetes from 211 countries covering upto $93.5 \%$ of adult population in the age group of 20-79 years. This data is alarming and warns us on the enormous increase in the prevalence of disease worldwide. ${ }^{2}$

Glycosylated hemoglobin is a type of hemoglobin in which glucose is irreversibly bound with it. Glycosylated hemoglobin is considered as a sensitive test for glycemic control in T2DM. It provides us an insight into the glycemic control of the patients for approximately last 
120 days. Major Diabetic trials like ACCORD, UKPDS and DCCT studies have shown that good glycemic control reduces the morbidity and mortality in diabetes mellitus. HbAlc value below $7 \mathrm{~g} \%$ would provide the patients with substantial life expectancy in diabetes mellitus. Hence in this study we consider patients with HbA1c below 7 as good glycemic control group. ${ }^{3,4}$

The CFF is considered as the frequency of an intermittent light source, at which the flicker sensation disappears and is replaced by the perception of a steady light. CFF is considered as a sensitive indicator to detect visual dysfunction in patients with maculopathy, retinopathy, neuropathy and glaucoma. CFF is also used as a tool to predict the cognitive functions and also assess the Central nervous system arousal. ${ }^{5,6}$

The objective of the study is to compare the CFF among the diabetics with differing glycemic control.

\section{Materials and Method}

The present study was conducted in the department of Physiology, Rajarajeswari Medical College and Hospital. Ethical committee approval was obtained. Sixty diabetic patients above the age of 35 years were recruited from the inpatient and outpatient department of Medicine. 30 patients had $\mathrm{HbA} 1 \mathrm{c}$ values $<7 \mathrm{~g} \%$ (Group I) and 30 had $\mathrm{HbA1c}$ values $>7 \mathrm{~g} \%$ (Group II). Written informed consent was obtained from subjects.
Inclusion Criteria: Diagnosed Type 2 diabetes mellitus patients of either gender above 35 years of age.

Exclusion Criteria: Patients associated with comorbid conditions like Hypertension, Hypothyroidism were not a part of this study. Patients suffering from any kind of Demyelinating disorders like Multiple sclerosis were excluded from the study.Patients with local eye diseases like cataract, ptosis and pterygium are also excluded from the present study.

CFF Apparatus: CFF was estimated using an inhouse built LED based CFF M1 model instrument which was pre-calibrated and checked for its performance. Stimulus light source was provided by a flickering red LED bulb (Light Emitting Diode, 5mm diameter, peak wavelength: $630 \mathrm{~nm}$ ) fixed in the centre of a white background. Flickering light had equal on and off periods. The stimulus was kept at a working distance of approximately $30 \mathrm{cms}$. The LED light was mounted at the centre of a white square screen $(15 \times 15 \mathrm{~cm})$. The examiner's panel has a knob to control the frequency of flicker in the red LED bulb (frequency range: 1 to 80 $\mathrm{Hz})^{7}$

Red light is perceived by the eyes for a longer time than any other color and hence we used a red LED light stimulus in this study. ${ }^{8}$

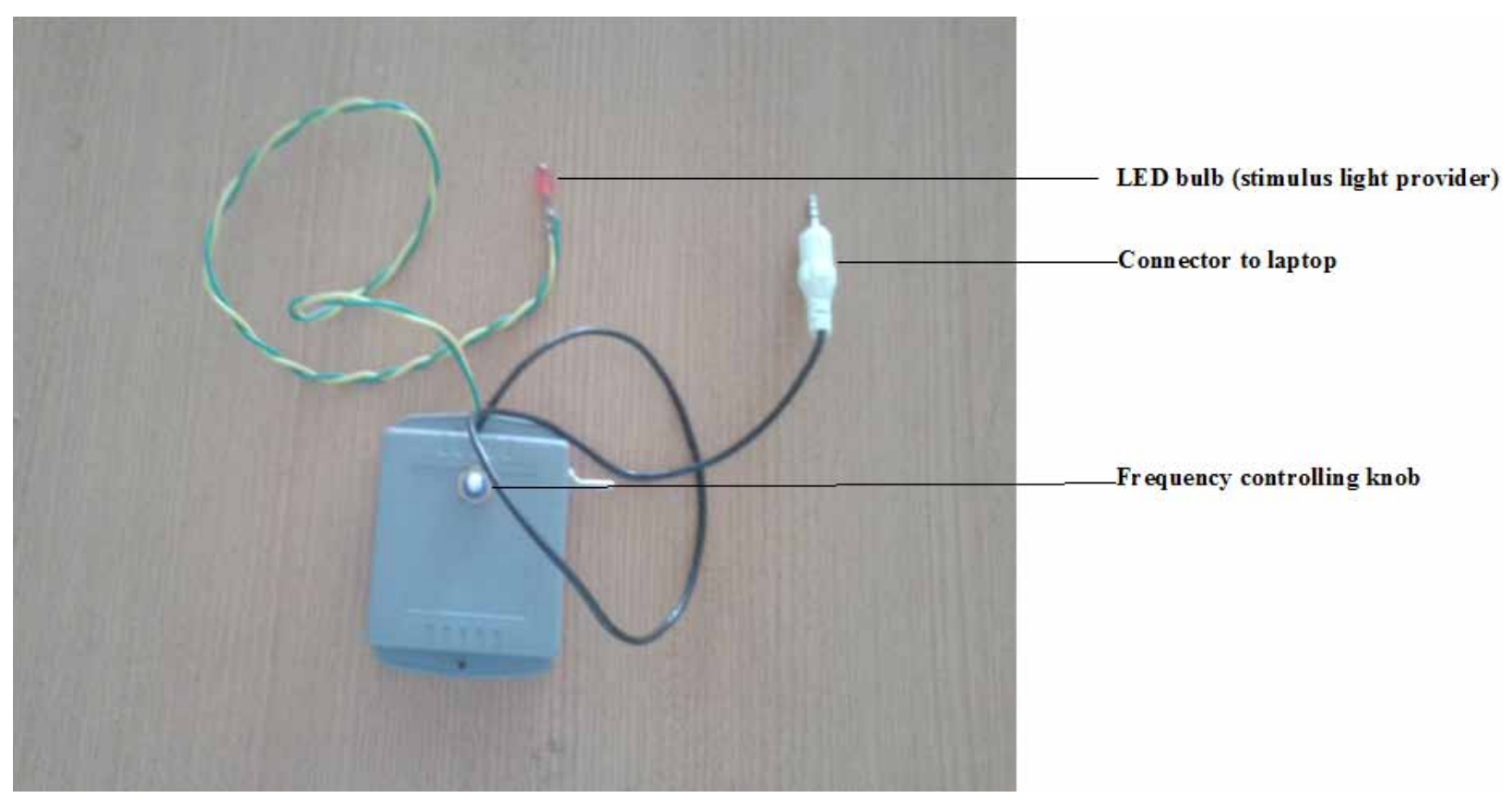

Figure 1: CFF measuring In-house built apparatu 
CFF measurement protocol: The LED's mean luminance was 50 micro candles and the white background of 150 lux illumination. Two diagonal red lines are drawn across the square screen and the LED is placed at the point of crossing of two lines. A control knob is provided in the LED driving device which can increase or decrease the frequency of flicker of the LED.

During experiment all overhead lights were switched off except a 40 watt tube light, fixed in the ceiling. CFF for each eye was recorded separately with the other eye closed by a cloth. The mean CFF is calculated by using both the readings. Subjects were seated comfortably such that the testing eye was $30 \mathrm{cms}$ from the light stimulus.
The subject was asked to indicate when the flickering light fused into a single steady light. The stimulus frequency was gradually increased by the examiner from $1 \mathrm{~Hz}$ until the light was perceived as steady by the subject.

The duration of the flicker $(\mathrm{T})$ at the frequency where the light was perceived as steady was noted using Audacity software. ${ }^{7} 3$ such trials were given to the subjects and the reading with longest flicker duration was considered for the study.

The CFF was calculated as $1 / \mathrm{T}$. The values were noted, tabulated and then analyzed.

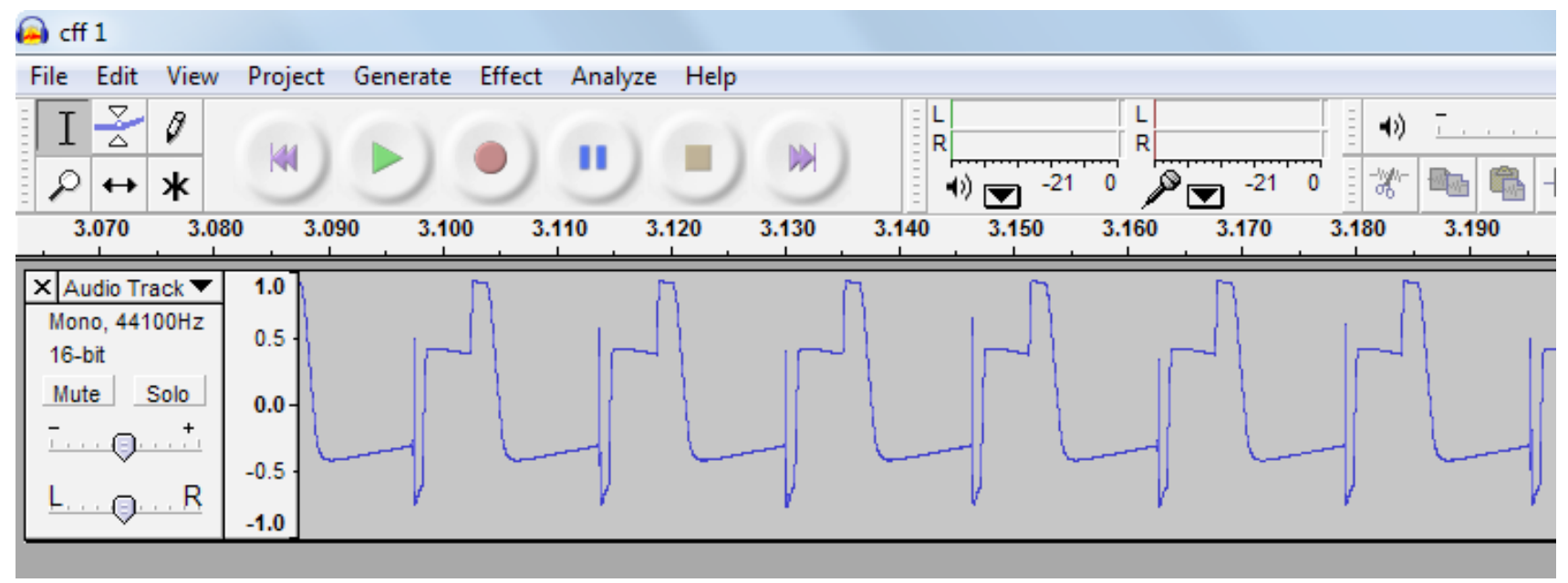

Figure 2: A sample recording of CFF by Audacity software

Results

Table 1: Gender and Age distribution between the groups

\begin{tabular}{|l|c|c|}
\hline \multirow{2}{*}{} & \multicolumn{2}{|c|}{ Age (Years) } \\
\cline { 2 - 3 } & Males & Females \\
\hline Group I & $53.05 \pm 8.8(\mathrm{n}=17)$ & $50.38 \pm 9.96(\mathrm{n}=13)$ \\
\hline Group II & $55.9 \pm 7.46(\mathrm{n}=20)$ & $51.3 \pm 11.23(\mathrm{n}=10)$ \\
\hline
\end{tabular}

Values in Mean+SD

Table 2: Comparison of Anthropometric data among the groups

\begin{tabular}{|l|c|c|c|}
\hline & Height $(\mathbf{c m s})$ & Weight $\mathbf{( K g )}$ & BMI $\left(\mathbf{K g} / \mathbf{m}^{\mathbf{2}}\right)$ \\
\hline Group I $\mathrm{n}=30$ & $162.56 \pm 7.56$ & $61.7 \pm 10.7$ & $23.17 \pm 2.628$ \\
\hline Group II $\mathrm{n}=30$ & $161.1 \pm 9.39$ & $62.3 \pm 6.81$ & $24.09 \pm 2.733$ \\
\hline
\end{tabular}

Values in Mean+SD 
Table 3: Comparison of CFF values among the groups

\begin{tabular}{|l|c|c|}
\hline & Group I, $\mathbf{n}=\mathbf{3 0}$ & Group II, $\mathbf{n = 3 0}$ \\
\hline HbAlc $(\mathrm{g} \%)$ & $6.16 \pm 0.5$ & $8.08 \pm 0.59^{\#}$ \\
\hline CFF (in Hz) & $30.17 \pm 4.69$ & $26.32 \pm 6.70^{*}$ \\
\hline
\end{tabular}

Values in Mean+SD, * - p >0.05, \# - p >0.0001

\section{Results}

The present study had subjects of both the Gender. The mean age of the subjects of either group was similar and comparable. There was no significant difference in the Anthropometric parameters between the groups. The mean BMI of the Group I subjects $(23.17+2.628)$ was comparable with that of Group II subjects (24.09+ 2.733).

The HbA1c values of Group I $(6.16+0.5)$ was significantly lower than Group II $(8.08+0.59)$. The mean CFF values in Group I and Group II were 30.17+4.69 and $26.32+6.70$ respectively. CFF values were significantly higher in Group I than Group II (P value > 0.05).

\section{Discussion}

CFF was significantly higher in the better glycemic control group (Group I) than the group with the poor glycemic control (Group II).Our study results are similar to the findings of another study by Stavrou E. P and Wood J M (2005).

Flickering stimuli produce a higher demand on the metabolic function of the photoreceptors in order for them to respond to the stimuli. Thus, as patients with diabetes have compromised metabolic control, the extra demand required to respond to flickering stimuli may result in significant reduction in the CFF in diabetes subjects. ${ }^{9}$

A similar result was also seen in another study conducted by Lobefalo L. et al in 1997. This study was conducted in 45 childrens suffering from IDDM. The age group of diabetic children was $9-18$ years. These children were assessed for diabetic retinopathy changes and they were included only if they did not have any retinopathy changes. Childrens with poorly controlled IDDM had a significantly lower CFF values compared to good metabolic control group. ${ }^{10}$

In a study conducted by Volbrecht et al, the CFF values improved (increased) as the blood sugar levels in the blood decreased in T2DM patients. According to that study, functional losses in diabetes patients are due to structural/vascular damage due to increased blood glucose levels. This results in blood vessel stress which itself may ultimately result in significant decreases in sensitivity. ${ }^{11}$

CFF is a very sensitive test and an optimal neurotransmission is a prerequisite for a higher CFF value. Any block in the transmission pathway will reduce the values of CFF. Any pathology involving the optic nerve transmission like optic neuropathy will definitely influence the values of CFF. ${ }^{12}$ Hyperglycemia in type 2 diabetes mellitus initiates the process of neuropathy during the course of the disease. Any neuropathic changes involving the optic nerve in T2DM can itself reduce the values of $\mathrm{CFF} .{ }^{13}$

Major limitation of CFF is its inability to differentiate between the retinal dysfunction and optic neuropathy, as CFF is altered in both the conditions. Fundoscopic evaluation of the subjects prior to measuring the $\mathrm{CFF}$ would help to provide more clarity with regards to the above limitation. This provides the scope for further research with $\mathrm{CFF}$ in diabetic patients.

\section{Conclusion}

CFF was significantly higher in better glycemic control group than the other group. This shows a better retinal function in better glycemic control group. Hence CFF can be used as a simple non-invasive bed side tool to assess the retinal and optic nerve function in type 2 diabetes mellitus patients.

Acknowledgement: I would like to thank $\mathrm{Dr}$ Maruthy K.N, Professor and HOD, Department of Physiology, Narayana Medical College, Nellore, Andhra Pradesh for providing the CFF measuring device. I also thank Dr Ranganath M D and all faculty members of Physiology department, Rajarajeswari Medical College 
and Hospital for their continued support and cooperation.

\section{Conflict of Interest: None}

Source of Funding: Personal funds

Ethical Clearance: Ethical clearance was obtained from the Institutional research and ethical committee board of Rajarajeswari Medical College and Hospital, Kumbalgod.

\section{References}

1. Diagnosis and classification of Diabetes mellitus. Diabetes care (serial online) 2008 January (cited 2013 October 10); 36 (1): S55 - S60. Available from: URL: http://care.diabetesjournals.org/ content/31/Supplement_1/S55.full.pdf + html

2. Saeedi P, Petersohn I, Salpea P, Malanda B, Karuranga S, Unwin $\mathrm{N}$ et al. Global and regional diabetes prevalence estimates for 2019 and projections for 2030 and 2045: Results from the International Diabetes Federation Diabetes Atlas, 9th edition. 2020.

3. Ian P. Glycosylated Haemoglobin: measurement and clinical use. Journal of Clinical Pathology. 1984; 37: $841-851$.

4. John B. B. Current Data reinforce HbA1c goal less than $7 \%$ (documentontheinternet). EndocrineToday. 2009 August (Cited 2013 October 9). Available from: http://www.healio.com/endocrinology/ diabetes/news/online/\%7B5daddece-55b9-48bdab03-92efb3cdac20\%7D/current-data-reinforcehbalc-goal-less-than-7

5. Guillermo Bueno del Romo, 1 William A. Douthwaite, 2 and David B. Elliott. Critical Flicker
Frequency as a Potential Vision Technique in the Presence of Cataracts. Investigative Ophthalmology \& Visual Science, March 2005, Vol. 46, No. 3. Pg no $1107-1112$.

6. Hindmarch I, Stonier P D, Curran S et al. Critical Flicker techniques in psychopharmacology. Human Psychopharmacology: Method and Measures. 1990; 3: 21 - 38 .

7. Niruba R, Babitha R, Maruthy K.N. Correlation between $\mathrm{CFF}$ and systolic blood pressure. National Journal of Physiology. 2013 October; 1(1): 11- 14.

8. Hema S, Konrad P. Critical flicker fusion test of potential vision. Journal of Cataract and refractive surgery. 2007 February; 33: 232 -9.

9. Central visual field changes using flicker Perimetry in type 2 diabetes mellitus. Efty P. Stavrou, Joanne M. Wood. Acta Ophthalmol. Scand. 2005: 83: 574580 .

10. Lobefalo L, Verrotti A, Mastropasqua L, Chiarelli F, Morgese G, Gallenga PE. Flicker perimetry in diabetic children without retinopathy. Canadian Journal of Ophthalmology. 1997 Aug; 32(5): 324-8.

11. Volbrecht VJ, Schneck ME, Adams AJ, Linfoot JA \& Ai E (1994): Diabetic short wave length sensitivity: variations with induced changes in blood glucose level. Investigative Ophthalmology and Visual Science. 35: 1243-1246.

12. Han DP, Thompson HS, Folk JC. Differentiation between recently resolved optic neuritis and central serous retinopathy; use of tests of visual function. Arch Ophthalmol 1985; 103:394-396.

13. Douglas Green. The pathogenesis and prevention of diabetic neuropathy and nephropathy. Metabolism. 1988 February; 37 (2): 25 - 29. 